\title{
Diversificação ou especialização: uma revisão sistemática à luz da Teoria do
}

\section{Comportamento Planejado}

\author{
Diversification of specialization: a systematic review in light of the Theory of Planned Behavior \\ Diversificación o especialización: una revisión sistemática a la luz de la Teoría del Comportamiento
}

Planificado

Recebido: 19/12/2021 | Revisado: 26/12/2021 | Aceito: 03/01/2022 | Publicado: 04/01/2022

Tiago Fernando Hansel
ORCID: https://orcid.org/0000-0002-9160-842X
Universidade Estadual do Oeste do Paraná, Brasil
Faculdade de Ensino Superior de Marechal Cândido Rondon, Brasil
E-mail: tiagohansel@hotmail.com
Geysler Rogis Flor Bertolini
ORCID: https://orcid.org/0000-0001-9424-4089
Universidade Estadual do Oeste do Paraná, Brasil
E-mail: geysler.bertolini@ unioeste.br
Ivano Ribeiro
ORCID: https://orcid.org/0000-0003-1113-2810
Universidade Estadual do Oeste do Paraná, Brasil
E-mail: ivano.adm@ gmail.com

\begin{abstract}
Resumo
O presente estudo tem como objetivo identificar na contemporaneidade estudos sobre a Teoria do Comportamento Planejado junto ao processo de tomada de decisão entre a diversificação ou especialização da produção da agricultura familiar. Para tanto, realizou-se pesquisa exploratória de caráter bibliográfica de revisão sistemática. O levantamento de dados se deu através de pesquisa nas plataformas Scopus e Web of Science. O processo de pesquisa ocorreu em duas etapas, na primeira realizou-se consulta nas plataformas através de palavras-chaves, e na segunda etapa, optou-se por publicações de autoria ou coautoria do criador da Teoria do Comportamento Planejado. Após processo de seleção de artigos foi possível à identificação das variáveis. Nos artigos selecionados através de pesquisa por palavras-chaves as variáveis notórias são: processo de tomada de decisão, análise de intenção, fatores psicológicos, análise comportamental, análise motivacional, estratégia e intuição. Já nos artigos selecionados pela autoria, as variáveis presentes são: análise comportamental, análise de intenção, análise de atitude, ação racional, estratégia e crenças. Para a ligação dos títulos dos estudos junto as suas variáveis, utilizou-se o software UCINET®. Como resultado identificou-se que a Teoria do Comportamento Planejado é eficaz para medir a intenção dos agricultores familiares no processo de tomada de decisão pela diversificação ou especialização da produção. Além disso, foi possível identificar que a intenção dos agricultores pela diversificação da produção é mais expressiva que a especialização, e que isso ocorre como uma estratégia de continuação das propriedades, segurança financeira e pela sustentabilidade. Sendo esses agricultores com pequenas áreas de terras, jovens e com menos recursos. Após análises, foi possível identificar que a Teoria do Comportamento Planejada está presente em vários estudos dos demais campos da ciência mundial.
\end{abstract}

Palavras-chave: Comportamento humano; Culturas; Intenção; Processo decisório.

\begin{abstract}
This study aims to identify contemporary studies on the Theory of Planned Behavior along with the decision-making process between diversification or specialization of family farming production. For that, an exploratory research of bibliographic character of systematic review was carried out. Data collection was carried out through research on the Scopus and Web of Science platforms. The research process took place in two stages, in the first stage, the platforms were consulted using keywords, and in the second stage, we opted for publications authored or co-authored by the creator of the Theory of Planned Behavior. After the article selection process, it was possible to identify the variables. In the articles selected through keyword research, the notorious variables are: decision-making process, intention analysis, psychological determination, behavioral analysis, motivational analysis, strategy and intuition. In the articles selected by the author, the variables present are: behavioral analysis, intention analysis, attitude analysis, rational action, strategy and beliefs. To link the titles of the studies together with their variables, use the UCINET® software. As a result, it was identified that the Theory of Planned Behavior is effective to assess the intention of family farmers in the decision-making process by diversifying or specializing the decision-making production. Furthermore, it was possible to identify that an intention of farmers to diversify production is more expressive than specialization, and that
\end{abstract}


this occurs as a strategy for the continuation of properties, financial security and sustainability. As these owners have small areas of land, they are young and have fewer resources. After analyses, it was possible to identify that the Theory of Planned Behavior is present in several studies in other fields of science worldwide.

Keywords: Cultures; Decision making process; Human behavior; Intention.

\section{Resumen}

Este estudio tiene como objetivo identificar estudios contemporáneos sobre la Teoría del Comportamiento Planificado en el proceso de toma de decisiones entre la diversificación o especialización de la producción agrícola familiar. Para ello, se realizó una investigación exploratoria de carácter bibliográfico de revisión sistemática. La recolección de datos se llevó a cabo mediante la investigación en las plataformas Scopus y Web of Science. El proceso de investigación se desarrolló en dos etapas, en la primera se consultaron las plataformas mediante palabras clave, y en la segunda etapa se optó por publicaciones de autoría o coautoría del creador de la Teoría del Comportamiento Planificado. Luego del proceso de selección de artículos, fue posible identificar las variables. En los artículos seleccionados a través de la investigación de palabras clave, las variables destacables son: proceso de toma de decisiones, análisis de intenciones, factores psicológicos, análisis conductual, análisis motivacional, estrategia e intuición. En los artículos seleccionados por el autor, las variables presentes son: análisis de comportamiento, análisis de intenciones, análisis de actitudes, acción racional, estrategia y creencias. Para vincular los títulos de los estudios con sus variables se utilizó el software UCINET®. Como resultado, se identificó que la Teoría del Comportamiento Planificado es eficaz para medir la intención de los agricultores familiares en el proceso de toma de decisiones para la diversificación o especialización de la producción. Además, se pudo identificar que la intención de los agricultores de diversificar la producción es más expresiva que la especialización, y que esto ocurre como una estrategia para la continuidad de las propiedades, la seguridad financiera y la sostenibilidad. Se trata de agricultores con pequeñas superficies de tierra, jóvenes y con menos recursos. Luego de los análisis, se pudo identificar que la Teoría del Comportamiento Planificado está presente en varios estudios en otros campos de la ciencia a nivel mundial.

Palabras clave: Comportamiento humano; Culturas; Intención; Proceso de toma de decisiones.

\section{Introdução}

Frequentemente surgem pesquisas relacionadas ao processo de tomada de decisão na agricultura, diversificação e especialização da produção agrícola, agricultura familiar e sobre a Teoria do Comportamento Planejado (Willock et al., 1999; Burton, 2004; Borges, 2015). Mesmo sendo frequentes as pesquisas sobre: tomada de decisão na agricultura, diversificação e especializa da produção, e Teoria do Comportamento Planejado, as pesquisas relacionando os temas são escassos.

A Teoria do Comportamento Planejado tem como objetivo medir o comportamento do indivíduo através da sua intenção. Para tanto, se trabalha com três constructos: atitude, norma subjetiva e o controle comportamental percebido (Ajzen \& Fishbein, 1980; Ajzen, 1991; Ajzen, 2005; Ajzen \& Sheikh, 2016; Senger, 2016; Senger et al., 2017).

Desde sua criação, essa teoria vem ganhando cada vez mais espaço no meio acadêmico, pelo seu vasto espaço de aplicabilidade nas mais diversas ciências. Pode-se citar Senger et al. (2017), Ajzen et al. (2019), Ajzen e Kruglanski (2019), Barbera e Ajzen (2020), Bosnijak et al. (2020), Ajzen (2020), Sok et al. (2020) e Barbera e Ajzen (2021) com estudos contemporâneos utilizando a Teoria do Comportamento Planejado para medir a intenção de indivíduos.

Da mesma maneira Valliant et al. (2017), Senger et al. (2017), Rosa et al. (2019) e Sok et al. (2020), possuem publicações recentes sobre a aplicabilidade da Teoria do Comportamento Planejado na agricultura familiar, bem como a medição da intenção desses agricultores em diversificar ou especializar a produção.

Neste contexto, o artigo se propõe a responder o seguinte questionamento: quais as características dos estudos científicos frente à utilização da Teoria do Comportamento Planejado sobre o processo de tomada de decisão dos agricultores familiares entre a diversificação ou a especialização da produção? Com o propósito de responder o questionamento da pesquisa, tem-se como objetivo central identificar através de pesquisa de revisão sistemática o que está sendo debatido no meio científico contemporâneo sobre a Teoria do Comportamento Planejado com relação ao processo de tomada de decisão dos agricultores familiares sobre diversificar ou especializar a produção. 
Este artigo se justifica em virtude da relevância do seu tema e os baixos números de estudos específicos da área. Além do mais, auxiliará pesquisadores a identificar títulos que abordam a temática. Também ajudará órgãos competentes a desenvolver políticas públicas para agricultores e para a sustentabilidade. Além disso, será aliado para pesquisadores da área a fomentar seus estudos. Ainda, agricultores familiares poderão utilizar-se dessa pesquisa para auxiliar no seu processo de tomada de decisão.

Dessa maneira, este estudo contribuirá para as pesquisas sobre a temática, bem como, abrirá alternativas para futuros estudos da área.

\section{Revisão Teórica}

\subsection{Teoria do Comportamento Planejado}

A Teoria do Comportamento Planejamento foi proposta em 1985 pelo psicólogo social Icek Ajzen. Para essa teoria um dos elementos centrais é explicar que a intenção do indivíduo em realizar um determinado comportamento. Para o criador da teoria, a intenção de agir é o determinante imediato do comportamento. Portando, quanto mais forte a intenção de se envolver em um comportamento, mais provável deve ser o seu desempenho (Ajzen \& Fishbein, 1980; Ajzen, 1991; Ajzen, 2005; Ajzen \& Sheikh, 2016; Senger, 2016; Borges, 2015; Burton, 2004; Willock et al., 1999).

A Teoria do Comportamento Planejado trabalha com três constructos: atitude, norma subjetiva e o controle comportamental percebido (Ajzen \& Fishbein, 1980; Ajzen, 1991; Ajzen, 2005; Ajzen \& Sheikh, 2016; Senger, 2016).

O constructo de atitude é a predisposição para responder a um objeto de uma maneira consistentemente favorável ou desfavorável. É o grau que um indivíduo tem para fazer uma avaliação favorável ou desfavorável de algum comportamento (Ajzen \& Fishbein, 1980; Ajzen, 1991; Ajzen, 2005; Ajzen \& Sheikh, 2016; Senger, 2016).

A norma subjetiva é a percepção do indivíduo que se preocupa com que a outra pessoa ou o grupo de pessoas pensam

acerca daquele que ele pertente concretizar. É a pressão social que o indivíduo sofre quando ele almeja realizar determinado comportamento (Ajzen \& Fishbein, 1980; Ajzen, 1991; Ajzen, 2005; Ajzen \& Sheikh, 2016; Senger, 2016).

Por fim, o controle comportamental percebido, é a facilidade ou a dificuldade do indivíduo de desempenhar o comportamento, no qual ele leva em conta as experiências passadas, bem como impedimentos antecipados e os obstáculos que enfrentará se tomar alguma decisão. É a percepção sobre sua própria capacidade. (Ajzen \& Fishbein, 1980; Ajzen, 1991; Ajzen, 2005; Ajzen \& Sheikh, 2016; Senger, 2016).

Portando, após análise desses constructos é possível medir qual a intenção dos indivíduos para um determinado comportamento. Por esse motivo, a Teoria do Comportamento Planejado é uma ferramenta importante para medir o nível de intenção dos agricultores familiares no processo de tomada de decisão, para definir se trabalharão com culturas produtivas diversas ou se irão se especializar, ou até mesmo, medir qual a intenção que esses agricultores têm de trocar seu formado de produção (Senger, 2016; Feitosa, 2017; Rosa, 2018).

\subsection{Processo de Tomada de Decisão}

O processo de tomada de decisão está presente no cotidiano de todos, da decisão mais simples de como decidir a roupa que devemos usar para ir trabalhar, como decisões mais sofisticadas, como investimentos financeiros. Nos dois casos, as pessoas tomam as suas decisões orientadas por suas experiências, crenças, percepções, informações, conhecimento próprio e de fatores externos. Nem sempre a decisão tomada leva à alternativa mais satisfatória, mas a mais aceitável ou razoável no processo de decisão (Simon, 1957; Simon, 1963; Gomes \& Gomes, 2019). 
Simon (1963), afirma que o processo de decisão compreende três fases principais, sendo a primeira a de descobrir as ocasiões em que deve ser tomada, na sequência, o tomador de decisão deverá identificar os possíveis cursos de ação e por fim, decidir pela opção mais sensata.

Esse processo pode ocorrer com modelos e técnicas estabelecidas e sofisticadas, como pode ocorrer sem nenhuma metodologia, mas sim, praticamente de forma inconsciente, através da sua intuição. Sendo assim, o processo de tomada de decisão pode ser racional ou não racional (Robbins et al., 2010; Gomes \& Gomes, 2019).

O processo de tomada de decisão racional tem como objetivo, se aproximar o máximo possível de uma decisão ideal, que objetiva a maximização dos resultados e o menor índice de erros ou consequências negativas (Simon, 1957; Simon, 1963; Maximiano, 2000; Balestrin, 2002; Choo, 2003; Barros, 2004; Dalcin, 2010; Gomes \& Gomes, 2019). Mas, é necessário ressaltar que o ser humano possui uma capacidade limitada, assim denominada por Simon (1957), para recepção, armazenamento e processamento de informação, o que dificulta um processo racional de tomada de decisões. Portando, ao decorrermos sobre a temática de processo de tomada de decisão, é necessário ressaltar que possuímos uma racionalidade limitada (Simon, 1957; Simon, 1979; Garner, 1982; Robbins et al., 2010; Spiegel \& Caulliraux, 2013).

Ao expressar a limitação da racionalidade, Simon (1957) afirma que há três dimensões causadoras dessa limitação: a informação disponível, a limitação cognitiva da mente dos indivíduos e o tempo disponível para o processo de tomada de decisão.

Simon (1963), considera que há dois tipos opostos de decisões, as programadas e as decisões não programadas, sendo as programadas decisões rotineiras. Ou seja, como o próprio termo já traz, são decisões sobre assuntos que já foram analisados anteriormente e que já se tem um determinado roteiro para a tomada de decisão. Já as decisões não programas, são aquelas não planejadas ou programadas, que surgem pela primeira vez e não se tem experiência para decidir.

Justamente, em virtude da limitação dos indivíduos em tomar decisões é que a Teoria do Comportamento Planejado se torna aliada e ganha espaço junto aos agricultores familiares no processo de decisão entre a diversificação ou especialização de culturas.

\subsection{Agricultura Familiar e a Diversificação e Especialização Produtiva}

Atualmente a agricultura familiar ganha grande notoriedade nas discussões no meio acadêmico, social e econômico, termologia esta considerada recente. Schneider (2003) define a agricultura familiar como uma atividade produtiva de pequeno porte, de um grupo social ligado por laços consanguíneos e de parentesco.

Schneider (1999) enfatiza que a agricultura familiar brasileira só ganha relevância nos estudos acadêmicos a partir de meados dos anos 1990, uma vez que até então, as preocupações se centravam na produção camponesa ou na pequena produção.

Quando se discute agricultura familiar, é de suma importância mencionar a Lei no 11.326, de 24 de julho de 2006, que estabelece as diretrizes para a formulação da Política Nacional da Agricultura Familiar e Empreendimentos Familiares Rurais. Através deste regulamento vários conceitos de agricultura familiar foram formalizados.

Na Lei no 11.326 , de 24 de julho de 2006, a agricultura familiar foi assim definida:

Art. $3^{\circ}$ Para os efeitos desta Lei, considera-se agricultor familiar e empreendedor familiar rural aquele que pratica atividades no meio rural, atendendo, simultaneamente, aos seguintes requisitos: I - não detenha, a qualquer título, área maior do que 4 (quatro) módulos fiscais;

II - utilize predominantemente mão de obra da própria família nas atividades econômicas do seu estabelecimento ou empreendimento;

III - tenha renda familiar predominantemente originada de atividades econômicas vinculadas ao próprio estabelecimento ou empreendimento; 
IV - dirija seu estabelecimento ou empreendimento com sua família.

$\S 1^{\circ} \mathrm{O}$ disposto no inciso I do caput deste artigo não se aplica quando se tratar de condomínio rural ou outras formas coletivas de propriedade, desde que a fração ideal por proprietário não ultrapasse 4 (quatro) módulos fiscais.

$\S 2^{\circ}$ São também beneficiários desta Lei:

I - silvicultores que atendam simultaneamente a todos os requisitos de que trata o caput deste artigo, cultivem florestas nativas ou exóticas e que promovam o manejo sustentável daqueles ambientes;

II - aquicultores que atendam simultaneamente a todos os requisitos de que trata o caput deste artigo e explorem reservatórios hídricos com superfície total de até 2 ha (dois hectares) ou ocupem até $500 \mathrm{~m}^{3}$ (quinhentos metros cúbicos) de água, quando a exploração se efetivar em tanques-rede;

III - extrativistas que atendam simultaneamente aos requisitos previstos nos incisos II, III e IV do caput deste artigo e exerçam essa atividade artesanalmente no meio rural, excluídos os garimpeiros e faiscadores;

IV - pescadores que atendam simultaneamente aos requisitos previstos nos incisos I, II, III e IV do caput deste artigo e exerçam a atividade pesqueira artesanalmente (Brasil, 2006).

Esta lei além de estabelecer diretrizes para a formulação da Política Nacional da Agricultura Familiar e Empreendimentos Familiares Rurais, também serviu como aliada na conceituação do termo agricultura familiar.

Ricardo Abramovay (1997), um dos principais cientistas brasileiros na temática da agricultura familiar, afirma que os três atributos básicos: gestão, propriedade e trabalho familiar, precisam estar presentes em uma propriedade para se considerar como agricultura familiar.

Desta maneira, pode-se conceituar agricultura familiar como o cultivo da terra realizado por pequenos proprietários rurais, tendo, como mão de obra, essencialmente, o núcleo familiar (Abramovay, 1992; Ploeg, 2016; Lamarche, 1999; Veiga, 1991; Veiga, 2007; Romeiro, 1998; Schneider, 2003; Plein, 2016).

Lamarche (1993) complementa que a exploração familiar, corresponde a uma unidade de produção agrícola, onde propriedade e trabalho estão intimamente ligados à família. A interdependência desses três fatores no funcionamento da exploração engendra necessariamente noções mais abstratas e complexas, tais como a transmissão do patrimônio e a reprodução da exploração.

No censo agropecuário de 2016, identificou-se que $84,4 \%$ do total de propriedades rurais brasileiras pertencem a grupos familiares. O que representa aproximadamente 4,4 milhões de unidades produtivas. Sendo assim, a agricultura familiar é responsável por uma grande fatia da representação econômica brasileira (IBGE, 2016).

A agricultura familiar possui suas especificações conforme a cultura e as tradições locais. Ela não segue apenas um padrão de produção, mas sim, se encaixa as peculiaridades regionais. $\mathrm{O}$ agricultor familiar remodela seu modo de produzir de acordo com as especificidades locais, ambientais, culturais dentre outros fatores (Amarante et al. 2018).

Nesse sentido, é relevante destacar que a definição pela diversificação ou pela especialização da produção dentro da agricultura familiar, por muitas vezes, serve de estratégia econômica, de mão de obra e de sustentabilidade.

A diversificação agrícola são as variedades produtivas em uma propriedade rural, muito utilizado para o produtor manter equilíbrio produtivo e financeiro. No caso de frustração de uma cultura, a outra que estiver em boas condições, manterá o sustento da propriedade (Perondi \& Schneider, 2011).

Schäffer (2011) afirma que o sistema de diversificação, visa adequar na agricultura familiar, de forma planejada, o maior número de opções que permitam no caso de frustração de uma alternativa, garantir a sua estabilidade e a geração de renda através das mais diversas alternativas produtivas.

A utilização da produção diversificada tornou-se também uma estratégia de diversificação econômica para os produtores rurais familiares. Portando, quando uma cultura não estiver rentável, a outra cultura dá o suporte necessário para manter o equilíbrio financeiro (Perondi \& Schneider, 2011; Hanzi, 2000; Schäffer, 2011; Colognese \& Stoffel, 2007). 
Em um estudo realizado por Perondi e Schneider (2011), sobre diversificação agrícola e não agrícola da agricultura familiar, os autores concluíram que propriedades rurais que possuem a metodologia da diversificação se desenvolvem mais do que aquelas que produzem apenas uma cultura.

Pensar em desenvolvimento rural é pensar que novas famílias estejam dispostas a suceder as atuais unidades de produção rural, sendo a elevação da renda per capita rural um efetivo caminho de realização deste objetivo. Portanto, parede ser preponderante pensar em políticas de incentivo à diversificação dos maios de vida nomeio rural visando, justamente, elevar a renda rural. Algo que contrasta ao senso comum daqueles que advogam que a renda rural somente poderia se elevar quando o agricultor estiver focado num único agronegócio. Comprovou-se assim que a renda é maior nas famílias que mais diversificam a renda (Perondi \& Schneider, 2011, p. 217).

Além do mais, a diversificação serve como grande aliada do meio ambiente, uma vez que nesse sistema a rotação de culturas é frequente, fazendo que o solo não sofra tanta degradação como na monocultura (Hanzi, 2000; Schäffer, 2011; Götsch, 2000; Guimarães, 1963; Graziano da Silva, 1978; Perondi \& Schneider, 2011; Colognese \& Stoffel, 2007).

Por outro lado, alguns produtores optam pela especialização da produção, que como o próprio nome expressa, é quando o agricultor busca se aperfeiçoar e trabalhar focado em uma cultura (Schneider, 2010; Hansson, 2011; Hoffmann, 1987).

A especialização da produção por muitas vezes pode proporcionar condições para a obtenção de ganhos devido à escala, melhor aproveitamento das instalações de beneficiamento, armazenamento e transporte, reduzindo os custos. No geral, nos sistemas especializados, a gestão é mais simples e o trabalho menos intenso, quando se compara com sistemas diversificados. Outro fator positivo da especialização de uma determinada atividade agrícola é a obtenção de conhecimentos mais aprofundados e específicos sobre a atividade em questão (Senger, 2016 \& Schneider, 2010; Hansson, 2011; Hoffmann, 1987).

Para Senger (2016, p. 24), uma propriedade é considerada especializada quando: " $50 \%$ ou mais da renda forem originários de uma única atividade rural, o estabelecimento agrícola foi considerado especializado, e, quanto maior for este valor, pode-se dizer que maior é sua especialização".

A especialização tem como principal desvantagem a fragilidade proporcionada para o produtor ou para uma região, se ocorrer uma adversidade climática numa determinada fase crítica do ciclo de uma cultura, bem como poderá ter a ocorrência de alguma doença na cultura ou baixas nos valores pagos e altos custos de produção. Além do mais, a especialização na agricultura, limita a adoção de uma prática fundamental quando se pensa em sustentabilidade, que é a rotação de culturas. Assim, a diversificação é fundamental quando se pensa em sustentabilidade (Schneider, 2010; Hansson, 2012; Norder, 2009; Ploeg \& Roep, 2003; Senger, 2016; Hoffmann, 1987; Ilbery, 1991; Ellis, 2000; Barbiery \& Mahoney, 2009; Turner et al., 2003; Graziano da Silva, 1992).

\section{Metodologia}

Um dos maiores desafios de acadêmicos e pesquisadores é a organização e estruturação de uma boa fundamentação teórica. Diariamente são divulgadas pesquisas em periódicos e, por esse motivo, é necessário à realização de uma ótima revisão sistêmica, pois da mesma forma como possuímos revistas sérias e criteriosas, temos no meio científico publicações que não seguem padrões de qualidade, seriedade e confiabilidade. Portando, a metodologia dessa pesquisa é uma análise sistêmica sobre a temática pesquisada em duas plataformas renomadas, através de palavras-chaves e trabalhos de autoria e coautoria do criador da teoria utilizada nesse estudo.

O processo de revisão sistêmica consiste na identificação, localização, compilação, análise e interpretação do conhecimento de fontes diversas como livros, artigos, relatórios, dissertações e teses, com a finalidade de encontrar 
conhecimentos aprofundados sobre o tema a ser pesquisado (Gil, 2007; Sampaio \& Mancini, 2007; Marconi \& Lakatos, 2010; Koller et al., 2014).

Sampaio e Mancini (2007) apresentam a pesquisa sistemática como "uma forma de pesquisa que utiliza como fonte de dados à literatura sobre determinado tema". Para os autores esse formato de pesquisa propicia um resumo das evidências relacionadas a uma estratégia de intervenção específica, mediante a aplicação de métodos explícitos e sistematizados de busca, apreciação crítica e síntese da informação selecionada. Sendo que os resultados dos trabalhos encontrados servem de base para pesquisadores trilharem novas pesquisas. Por esse motivo, optou-se por esse tipo de pesquisa, haja vista que após essa consulta, saberemos o que já foi pesquisado e quais as lacunas ainda não foram respondidas no meio cientifico sobre os temas.

Optou-se por duas plataformas renomadas no campo da ciência. A primeira utilizada foi a Scopus, de origem holandesa que possui mais de 19 mil títulos de mais de 5.000 editoras internacionais, incluindo a cobertura de 16.500 revistas. A outra plataforma de pesquisa utilizada é a britânica Web of Science, que da mesma maneira que a anterior, é uma ferramenta de pesquisa unificadora que permite ao usuário adquirir, analisar e disseminar informações do banco de dados em tempo hábil, além disso, ela abrange mais de 50 mil livros acadêmicos, 12 mil periódicos e 160 mil anais de conferências.

A primeira etapa da pesquisa foi realizada com palavras-chaves, na qual foram definidas 05 palavras, para tentar afunilamento máximo de trabalhos. Como as duas plataformas citadas estão em inglês, às palavras utilizadas foram: Theory of Planned Behavior (Teoria do Comportamento Planejado), Decision Making (Tomada de Decisão), Family Farming (Agricultura Familiar), Diversification (Diversificação) e Specialization (Especialização).

A utilização da estratégia de 05 palavras teve êxito na Scopus já na Web Of Science não se obteve sucesso, sendo necessária a eliminação das duas últimas palavras para localizar estudos.

Além disso, realizou-se pesquisa na Scopus e na Web of Science de trabalhos de autoria ou coautoria do fundador da Teoria do Comportamento Planejado, Icek Ajzen, tendo em vista que ele está ativamente realizando pesquisas e dando publicidade a estes estudos e, por esse motivo acreditou-se ser interessante identificar pensamentos clássicos e contemporâneos sobre a temática na visão do autor.

Como critério de inclusão através da pesquisa com palavras-chaves, na Scopus e na Web of Science delimitou-se ser classificado como artigo, estar com acesso livre e com a publicação entre os anos de 2007 a 2021. Já na consulta pela autoria, às pesquisas ocorreram apenas nas Plataformas Scopus e Web of Science sem delimitação de anos de publicação com a justificativa de acreditar que o número de publicações seria menor, sendo que os demais critérios foram respeitados.

Como critério de exclusão, realizou-se análise dos resumos e, quando necessário, do texto completo. Foram excluídos os artigos que não se enquadraram no objetivo proposto pelo estudo e trabalhos que não apresentavam o texto completo de livre acesso. Os resultados estão apresentados no Quadro 1:

Quadro 1. Seleção de trabalhos.

\begin{tabular}{|c|c|c|}
\hline \multicolumn{3}{|c|}{ Pesquisa com palavras-chaves } \\
\hline Plataforma & Total de trabalhos encontrados & Total de trabalhos selecionados \\
\hline Scopus & 164 & 07 \\
\hline Web of Science & 15 & 03 \\
\hline \multicolumn{3}{|c|}{ Pesquisa de autoria de Icek Ajzen } \\
\hline Plataforma & Total de trabalhos encontrados & Total de trabalhos selecionados \\
\hline Scopus & 07 & 06 \\
\hline Web of Science & 109 & 14 \\
\hline
\end{tabular}

Fonte. Elaborado pelos autores da pesquisa (2021).

Portando, após o processo de exclusão, na etapa de revisão com palavras-chaves obteve-se a classificação de 10 pesquisas. Já na consulta por trabalhos de autoria foram selecionas 20 artigos. 
Para a verificação da relação dos títulos e principais variáveis estudadas, utilizou-se o software UCINET®, cuja principal função é a de criação e manipulação de matrizes que representam matematicamente as redes, onde os seus elementos são as relações.

\section{Resultados e Discussão}

A partir desse momento serão apresentados os artigos selecionados para auxiliar a responder à pergunta dessa pesquisa. Para tanto, foram estruturados 04 quadros, com os resultados obtidos nas plataformas pesquisadas.

No Quadro 2, estão contidos resultados das consultas realizados na plataforma Scopus que é um dos maiores e mais expressivos bancos de dados de artigos científicos. Esta plataforma seleciona artigos das principais revistas cientificas mundiais. Após a consulta com as 05 palavras chaves já mencionadas anteriormente, selecionou-se 07 artigos.

Quadro 2. Dados dos artigos selecionados por palavras-chaves na Plataforma Scopus.

\begin{tabular}{|c|c|c|c|c|}
\hline \multicolumn{5}{|c|}{ Plataforma: Scopus } \\
\hline $\mathbf{N}^{0}$ & Autores & Título & Revista & País \\
\hline 01 & $\begin{array}{l}\text { Marcello de Rosa, } \\
\text { Gerard McElwee, } \\
\text { Robert Smith, }\end{array}$ & $\begin{array}{l}\text { Farm diversification strategies in response to } \\
\text { rural policy: a case from rural Italy }\end{array}$ & $\begin{array}{l}\text { Land Use Policy } \\
\text { Volume } 81, \text { February 2019, Pages } \\
\text { 291-301 }\end{array}$ & Itália \\
\hline 02 & $\begin{array}{c}\text { Meike Weltin, } \\
\text { Ingo Zasada, } \\
\text { Christian Franke, } \\
\text { Annette Piorr, Meri } \\
\text { Raggi, Davide Viaggi. }\end{array}$ & $\begin{array}{l}\text { Analysing behavioural differences of farm } \\
\text { households: An example of income } \\
\text { diversification strategies based on European } \\
\text { farm survey data; }\end{array}$ & $\begin{array}{c}\text { Land Use Policy } \\
\text { Volume 62, March 2017, Pages 172- } \\
184\end{array}$ & Alemanha \\
\hline 03 & $\begin{array}{l}\text { Rob Smith, } \\
\text { Gerard McElwee, } \\
\text { Peter Somorviller. }\end{array}$ & $\begin{array}{l}\text { Illegal diversification strategies in the } \\
\text { farming community from a UK perspective; }\end{array}$ & $\begin{array}{c}\text { Journal of Rural Studies. } \\
\text { Volume 53, July 2017, Pages 122- } \\
131 \\
\end{array}$ & Reino Unido \\
\hline 04 & $\begin{array}{c}\text { Igor Senger, } \\
\text { João Augusto Rossi } \\
\text { Borges, João Armando } \\
\text { Dessiomon Machado. }\end{array}$ & $\begin{array}{c}\text { Using structural equation modeling to } \\
\text { identify the psychological factors influencing } \\
\text { dairy farmers' intention to diversify } \\
\text { agricultural production }\end{array}$ & $\begin{array}{c}\text { Livestock Science } \\
\text { Volume 203, September 2017, } \\
\text { Pages 97-105 }\end{array}$ & Brasil \\
\hline 05 & $\begin{array}{c}\text { Julia C.D. Valliant, } \\
\text { James R. Farmer, } \\
\text { Stephanie L. Dickinson, } \\
\text { Analena B. Bruce, } \\
\text { Jennifer Meta Robinson. }\end{array}$ & $\begin{array}{l}\text { Family as a catalyst in farms' diversifying } \\
\text { agricultural products: A mixed methods } \\
\text { analysis of diversified and non-diversified } \\
\text { farms in Indiana, Michigan and Ohio; }\end{array}$ & $\begin{array}{l}\text { Journal of Rural Studies } \\
\text { Volume 55, October 2017, Pages } \\
\text { 303-315 }\end{array}$ & Estados Unidos \\
\hline 06 & $\begin{array}{c}\text { Ana Isabel García - } \\
\text { Arias, } \\
\text { Ibán Vázques-Gonzáles, } \\
\text { Frnacisco Sineiro - } \\
\text { García, } \\
\text { Mar Pérez -Fra. }\end{array}$ & $\begin{array}{c}\text { Farm diversification strategies in } \\
\text { northwestern Spain: Factors affecting } \\
\text { transitional pathways }\end{array}$ & $\begin{array}{c}\text { Land Use Policy } \\
\text { Volume 49, December 2015, Pages } \\
413-425\end{array}$ & Espanha \\
\hline 07 & $\begin{array}{l}\text { Paul Wilson, } \\
\text { Nicholas Hasper, } \\
\text { Richard Darling. }\end{array}$ & $\begin{array}{l}\text { Explaining variation in farm and farm } \\
\text { business performance in respect to farmer } \\
\text { behavioural segmentation analysis: } \\
\text { Implications for land use policies }\end{array}$ & $\begin{array}{c}\text { Land Use Policy } \\
\text { Volume } 30, \text { Issue } 1 \text {, January } 2013 \text {, } \\
\text { Pages } 147-156\end{array}$ & Reino Unido \\
\hline
\end{tabular}

Fonte. Elaborado pelos autores da pesquisa (2021).

É possível averiguar que os trabalhos selecionados são advindos de 03 revistas ligadas as ciências agrarias, 04 da Land Use Policy, 02 da Journal of Rural Studies e 01 da Livestock Science. Dessa maneira pode-se afirmar com segurança que esses artigos estão publicados em revistas de excelente qualidade (Quadro 2).

Dos artigos selecionados, 04 foram publicados no ano de 2017, 01 em 2019, 01 em 2015 e 01 em 2013 (Quadro 02). Destaca-se que o ano de 2017 teve maior índice de pesquisas sobre o tema. Dessa maneira, podemos considerar que são artigos contemporâneos. Além disso, todos os trabalhos estão publicados em inglês.

Em relação aos países em que foram realizadas essas pesquisas, obteve-se um misto de localidades, sendo que duas pesquisas são originarias do Reino Unido, já as demais pesquisas foram realizadas uma em cada dos países seguintes: Alemanha, Brasil, Espanha, Estados Unidos da América e Itália (Quadro 02). Esse fenômeno é importante para essa pesquisa, 
pois traz realidades de estudos de diversos lugares. Durante a consulta, percebeu-se a riqueza de publicações dessas localidades.

Como o foco dessa pesquisa é a Teoria do Comportamento Planejado, viu-se a necessidade de pesquisar e identificar artigos do fundador dessa teoria. Icek Ajzen é um psicólogo, escritor e pesquisador com diversos estudos contemporâneos. Por esse motivo, a segunda pesquisa na Plataforma Scopus não foi realizada com palavras-chaves, mas pela autoria, com isso, obtiveram-se os resultados apresentados no Quadro 3:

Quadro 3. Dados dos artigos selecionados pelo autor na Plataforma Scopus:

\begin{tabular}{|c|c|c|c|c|}
\hline \multicolumn{5}{|c|}{ Plataforma: Scopus } \\
\hline $\mathrm{N}^{0}$ & Autores & Título & Revista & País \\
\hline 01 & Icek Ajzen. & The theory of planned behavior. & $\begin{array}{c}\text { Organizational Behavior } \\
\text { and Human Decision } \\
\text { Processes } \\
\text { Volume 50, Issue } \\
\text { 2, December 1991, Pages } \\
\text { 179-211 } \\
\end{array}$ & Estados Unidos \\
\hline 02 & Icek Ajzen. & $\begin{array}{l}\text { Attitudes, Traits, and Actions: Dispositional } \\
\text { Prediction of Behavior in Personality and } \\
\text { Social Psychology }\end{array}$ & $\begin{array}{c}\text { Advances in Experimental } \\
\text { Social Psychology } \\
\text { Volume 20, 1987, Pages } \\
1-63 .\end{array}$ & Estados Unidos \\
\hline 03 & $\begin{array}{l}\text { Icek Ajzen, } \\
\text { Thomas J. Madden. }\end{array}$ & $\begin{array}{l}\text { Prediction of goal-directed behavior: } \\
\text { Attitudes, intentions, and perceived } \\
\text { behavioral control. }\end{array}$ & $\begin{array}{c}\text { Journal of Experimental } \\
\text { Social Psychology } \\
\text { Volume 22, Issue } \\
\text { 5, September 1986, Pages } \\
\text { 453-474. } \\
\end{array}$ & Estados Unidos \\
\hline 04 & $\begin{array}{l}\text { Carol Ann Dalto, } \\
\text { Icek Ajzen, } \\
\text { Kalman J. Kaplan. }\end{array}$ & $\begin{array}{l}\text { Self-disclosure and attraction: Effects of } \\
\text { intimacy and desirability on beliefs and } \\
\text { attitudes }\end{array}$ & $\begin{array}{c}\text { Journal of Research in } \\
\text { Personality } \\
\text { Volume 13, Issue 2, June } \\
\text { 1979, Pages 127-138 } \\
\end{array}$ & Estados Unidos \\
\hline 05 & $\begin{array}{l}\text { Icek Ajzen, } \\
\text { Martin Fishbein. }\end{array}$ & $\begin{array}{l}\text { The prediction of behavior from attitudinal } \\
\text { and normative variables }\end{array}$ & $\begin{array}{l}\text { Journal of Experimental } \\
\text { Social Psychology } \\
\text { Volume 6, Issue } \\
\text { 4, October 1970, Pages } \\
\text { 466-487 } \\
\end{array}$ & Estados Unidos \\
\hline 06 & $\begin{array}{l}\text { Icek Ajzen, } \\
\text { Martin Fishbein. }\end{array}$ & $\begin{array}{l}\text { The prediction of behavioral intentions in a } \\
\text { choice situation }\end{array}$ & $\begin{array}{l}\text { Journal of Experimental } \\
\text { Social Psychology } \\
\text { Volume 5, Issue } \\
\text { 4, October 1969, Pages } \\
\text { 400-416 } \\
\end{array}$ & Estados Unidos \\
\hline
\end{tabular}

Fonte. Elaborado pelos autores da pesquisa (2021).

Quando a pesquisa foi realizada com o nome de Icek Ajzen, fundador da Teoria do Comportamento Planejado, na plataforma Scopus, obteve-se 15 resultados, sendo 06 selecionados para agregar nas respostas do problema de pesquisa proposto neste estudo.

Todos os artigos elencados possuem ligação com a Teoria do Comportamento Planejado, tendo relação direta ou indireta com o processo de tomada de decisão da agricultura familiar.

Dos artigos filtrados, 02 são escritos apenas pelo autor da teoria, os demais contam com participação de outros pesquisadores. Mas é necessário ressaltar os 02 artigos escritos pelo autor em conjunto com Martin Fishbein, pois foram eles os criadores da Teoria da Ação Racional, está que antecede a Teoria do Comportamento Planejado (Quadro 03). A Teoria da Ação Racional foi desenvolvida por Fishbein e Ajzen em 1967 com o objetivo de explicar a relação entre atitudes e comportamentos dentro da ação humana. Mas, após alguns anos, Ajzen aperfeiçoou essa teoria, com mais um constructo, mas objetivando a mesma finalidade. Desta maneira, nasce a Teoria do Comportamento Planejado.

As revistas utilizadas para publicação estão ligadas ao comportamento humano e psicologia. O autor repetiu apenas a revista Journal of Experimental Social Psychology no qual publicou 03 dos trabalhos selecionados, já nas revistas 
Organization Behavior and Human Decision Processes, Advances in Experimental Social Psychology e Journal of Reseanch in Personality publicou um artigo em cada. Todas as revistas conceituadas na área (Quadro 3).

Sobre os anos de publicação, na tabela anterior delimitaram-se os últimos 15 anos como um dos critérios de seleção, pensando em contemporaneidade, mas em virtude do conhecimento do ano (1985) do surgimento da Teoria do Comportamento Planejado, nessa tabela não foi delimitado datas. Portanto, os artigos apresentados aqui, são dos anos de 1969, 1970, 1979, 1986, 1987 e 1991 (Quadro 3). Podemos perceber que há artigos publicados antes da data da publicação da Teoria do Comportamento Planejado, mas que se justifica pelo fato de, até então, termos a Teoria da Ação Racional, que trabalhava praticamente os mesmos pressupostos. E como já mencionado anteriormente, a Teoria do Comportamento Planejado pode ser considerada uma atualização da Teoria da Ação Racional.

Todas as pesquisas elencadas neste estudo são americanas, hipótese para isso é o fato de que além de ser psicólogo social, Icek Ajzen é professor e pesquisador da Universidade de Massachusetts Amherst, no qual realiza inúmeras pesquisas as quais lhe trouxeram vários prêmios e títulos. Além disso, ele foi classificado como o cientista individual mais influente dentro da psicologia social (ROTH, 2016). Portando, talvez por esse motivo, suas pesquisas estejam centralizadas nos Estados Unidos.

$\mathrm{Na}$ sequência, realizou-se o mesmo roteiro das duas pesquisas anteriores, primeiramente com palavras-chaves e posteriormente pesquisas pelo autor, mas desta vez na Plataforma Web of Science. Outro sítio de alta qualidade pelas pesquisas inovadoras e de excelência e que traz. Os resultados estão apresentados no Quadro 4:

Quadro 4. Dados dos artigos selecionados por palavras-chaves na Plataforma Web of Science.

\begin{tabular}{|c|c|c|c|c|}
\hline \multicolumn{5}{|c|}{ Plataforma: Web of Science } \\
\hline $\mathbf{N}^{\mathbf{0}}$ & Autores & Título & Revista & País \\
\hline 01 & $\begin{array}{c}\text { Amar Daxini, } \\
\text { Mary Ryan, } \\
\text { Cathal O'Donoghue, } \\
\text { Andrew P Barnes. }\end{array}$ & $\begin{array}{l}\text { Understanding farmers' intentions to follow a } \\
\text { nutrient management plan using the theory of } \\
\text { planned behaviour }\end{array}$ & $\begin{array}{l}\text { Land Use Policy Volume: } \\
\text { 85 Páginas: 428-437 } \\
\text { Publicado: JUN } 2019\end{array}$ & Inglaterra \\
\hline 02 & Nathall PL, Old Km. & $\begin{array}{c}\text { Intuition, the farmers' primary decision } \\
\text { process. A review and analysis }\end{array}$ & $\begin{array}{c}\text { Journal Of Rural Studies } \\
\text { Volume: } 58 \\
\text { Páginas: } 28-38 . \\
\text { Publicado: FEB } 2018\end{array}$ & Inglaterra \\
\hline 03 & $\begin{array}{l}\text { Lili A. Schroeder, } \\
\text { Steplen Chaplin, } \\
\text { Johannes Isselstein. }\end{array}$ & $\begin{array}{c}\text { What influences farmers' acceptance of agri- } \\
\text { environment schemes? An ex-post } \\
\text { application of the 'Theory of Planned } \\
\text { Behaviour' }\end{array}$ & $\begin{array}{l}\text { Landbau Forschung } \\
\text { Volume: } 65 \text { Edição: } 1 \\
\text { Páginas: 15-28 } \\
\text { Publicado: MAR 2015 }\end{array}$ & Alemanha \\
\hline
\end{tabular}

Fonte. Elaborado pelos autores da pesquisa (2021).

Mesmo com o afunilamento de palavras-chaves, os trabalhos encontrados vêm de encontro com o problema de pesquisa desse estudo. Publicados em periódicos distintos, mas ligados às ciências agrárias. As três publicações ocorrem em diferentes anos, um em 2019, outro em 2018 e por fim um em 2015. Podemos assim, considerar que são trabalhos modernos. (Quadro 4).

Duas pesquisas foram realizadas na Inglaterra e a outra na Alemanha (Quadro 04). Países com bons investimentos em ciências, os quais já apresentaram diversas pesquisas relevantes para a humanidade, além de ter vários pesquisadores conceituados nas áreas do comportamento humano.

Mesmo com número menor de resultados que os apresentados na plataforma anterior, manteve-se a qualidade intelectual.

Também, como na plataforma anterior, realizou-se pesquisa de artigos pela autoria do idealizador da Teoria do Comportamento Planejado. Da mesma forma, não se utilizou de critérios de periodicidade de publicação. No qual, obteve-se os seguintes resultados: 
Research, Society and Development, v. 11, n. 1, e15211124934, 2022

(CC BY 4.0) | ISSN 2525-3409 | DOI: http://dx.doi.org/10.33448/rsd-v11i1.24934

Quadro 5. Dados dos artigos selecionados pelo autor na Plataforma Web of Science.

\begin{tabular}{|c|c|c|c|c|}
\hline \multicolumn{5}{|c|}{ Plataforma: Web of Science } \\
\hline $\mathbf{N}^{\mathbf{o}}$ & Autores & Título & Revista & País \\
\hline 01 & $\begin{array}{l}\text { Francesco La Barbera, } \\
\text { Icek Ajzen. }\end{array}$ & $\begin{array}{c}\text { Moderating role of perceived behavioral } \\
\text { control in the theory of planned behavior: A } \\
\text { preregistered study }\end{array}$ & $\begin{array}{c}\text { Journal Of Theoretical Social } \\
\text { Psychology } \\
\text { Volume: } 5 \text { Edição: } 1 \\
\text { Páginas: } 35-45 \\
\text { Publicado: JAN } 2021 \text {. }\end{array}$ & Estados Unidos \\
\hline 02 & $\begin{array}{l}\text { Jaap Sok, João Rossi } \\
\text { Borges, } \\
\text { Peter Schmidt, Icek } \\
\text { Ajzen. }\end{array}$ & $\begin{array}{c}\text { Farmer Behaviour as Reasoned Action: A } \\
\text { Critical Review of Research with the Theory } \\
\text { of Planned Behaviour }\end{array}$ & $\begin{array}{c}\text { Journal Of Agricultural Economics } \\
\text { Volume: } 72 \\
\text { Edição: } 2 \\
\text { Páginas: } 388-412 \\
\text { Publicado: JUN } 2020 .\end{array}$ & Estados Unidos \\
\hline 03 & Icek Ajzen. & $\begin{array}{l}\text { The theory of planned behavior: Frequently } \\
\text { asked questions }\end{array}$ & $\begin{array}{c}\text { Human Behavior and Emerging } \\
\text { Technologies } \\
\text { Volume: } 2 \\
\text { Edição: } 4 \\
\text { Páginas: } 314-324 \\
\text { Publicado: OCT } 2020 \\
\end{array}$ & Estados Unidos \\
\hline 04 & $\begin{array}{l}\text { Michael Bosnijak, } \\
\text { Icek Ajzen, } \\
\text { Peter Schmidt. }\end{array}$ & $\begin{array}{c}\text { The Theory of Planned Behavior: Selected } \\
\text { Recent Advances and Applications }\end{array}$ & $\begin{array}{c}\text { Europes Journal of Psychology } \\
\text { Volume: } 16 \\
\text { Edição: } 3 \\
\text { Páginas: } 352-356 \\
\text { Publicado: AUG } 2020 \\
\end{array}$ & Alemanha \\
\hline 05 & $\begin{array}{l}\text { Francesco La Barbera, } \\
\text { Icek Ajzen. }\end{array}$ & $\begin{array}{c}\text { Control Interactions in the Theory of Planned } \\
\text { Behavior: Rethinking the Role of Subjective } \\
\text { Norm }\end{array}$ & $\begin{array}{c}\text { Europes Journal of Psychology } \\
\text { Volume: } 16 \\
\text { Edição: } 3 \\
\text { Páginas: 401-417 } \\
\text { Publicado: AUG } 2020\end{array}$ & Alemanha \\
\hline 06 & $\begin{array}{l}\text { Icek Ajzen, } \\
\text { Ariei Kruglanski. }\end{array}$ & $\begin{array}{l}\text { Reasoned Action in the Service of Goal } \\
\text { Pursuit }\end{array}$ & $\begin{array}{l}\text { Psychological Review } \\
\text { Volume: } 126 \\
\text { Edição: } 5 \\
\text { Páginas: } 774-786 \\
\text { Publicado: OCT } 2019\end{array}$ & Estados Unidos \\
\hline 07 & $\begin{array}{l}\text { Icek Ajzen, } \\
\text { Martin Fishbein, } \\
\text { Sophie Lohmann, } \\
\text { Dolores Albarracin }\end{array}$ & The influence of attitudes on behavior & $\begin{array}{l}\text { Handbook of Attitudes, Vol 1: } \\
\text { Páginas: 197-255 } \\
\text { Publicado: } 2019\end{array}$ & Inglaterra \\
\hline 08 & $\begin{array}{l}\text { Icej Ajzen, } \\
\text { Sana Sheikh. }\end{array}$ & $\begin{array}{l}\text { Action versus inaction: anticipated affect in } \\
\text { the theory of planned behavior }\end{array}$ & $\begin{array}{c}\text { Journal of Applied Social } \\
\text { Psychology } \\
\text { Volume: } 46 \\
\text { Edição: } 5 \\
\text { Páginas: } 313-314 \\
\text { Publicado: MAY } 2016\end{array}$ & Estados Unidos \\
\hline 09 & $\begin{array}{l}\text { Holger Steinmetz, } \\
\text { Michael Knappstein, } \\
\text { Icek Ajzen, } \\
\text { Peter Scmidt, } \\
\text { Ruediger Kabst. }\end{array}$ & $\begin{array}{c}\text { How Effective are Behavior Change } \\
\text { Interventions Based on the Theory of } \\
\text { Planned Behavior? A Three-Level Meta- } \\
\text { Analysis }\end{array}$ & $\begin{array}{l}\text { Zeitschrift Fur Psychologie-Journal } \\
\text { of Psychology } \\
\text { Volume: } 224 \\
\text { Edição: } 3 \\
\text { Páginas: } 216-233 \\
\text { Publicado: } 2016 \\
\end{array}$ & Alemanha \\
\hline 10 & $\begin{array}{l}\text { Icej Ajzen, } \\
\text { Sana Sheikh. }\end{array}$ & $\begin{array}{l}\text { Action versus inaction: anticipated affect in } \\
\text { the theory of planned behavior }\end{array}$ & $\begin{array}{c}\text { Journal of Applied Social } \\
\text { Psychology } \\
\text { Volume: } 43 \\
\text { Edição: } 1 \\
\text { Páginas: } 155-162 \\
\text { Publicado: JAN } 2013 \\
\end{array}$ & Estados Unidos \\
\hline 11 & Icej Ajzen & $\begin{array}{l}\text { Martin Fishbein's legacy: The reasoned } \\
\text { action approach }\end{array}$ & $\begin{array}{c}\text { Annals of The American Academy } \\
\text { of Political and Social Science } \\
\text { Volume: } 643 \\
\text { Páginas: } 267-267\end{array}$ & Estados Unidos \\
\hline
\end{tabular}


Research, Society and Development, v. 11, n. 1, e15211124934, 2022

(CC BY 4.0) | ISSN 2525-3409 | DOI: http://dx.doi.org/10.33448/rsd-v11i1.24934

\begin{tabular}{|c|c|c|c|c|}
\hline & & & Publicado: SEP 2012 & \\
\hline 12 & $\begin{array}{c}\text { Icek Ajzen, } \\
\text { Nicholas Joyce, } \\
\text { Sana Sheikh, } \\
\text { Nicole Gilbert Cote. }\end{array}$ & $\begin{array}{l}\text { Knowledge and the Prediction of Behavior: } \\
\text { The Role of Information Accuracy in the } \\
\text { Theory of Planned Behavior }\end{array}$ & $\begin{array}{c}\text { Basic and Applied Social } \\
\text { Psychology } \\
\text { Volume: } 33 \\
\text { Edição: } 2 \\
\text { Páginas: } 101-117 \\
\text { Publicado: } 2011\end{array}$ & Estados Unidos \\
\hline 13 & Icek Ajzen. & $\begin{array}{l}\text { The theory of planned behaviour: Reactions } \\
\text { and reflections }\end{array}$ & $\begin{array}{l}\text { Psychology and Health } \\
\text { Volume: } 26 \\
\text { Edição: } 9 \\
\text { Páginas: } 1113-1127 \\
\text { Publicado: } 2011 . \\
\end{array}$ & Inglaterra \\
\hline 14 & $\begin{array}{c}\text { Icek Ajzen, } \\
\text { Cornelia Czasch, } \\
\text { Michael G. Flood. }\end{array}$ & $\begin{array}{c}\text { From Intentions to Behavior: Implementation } \\
\text { Intention, Commitment, and } \\
\text { Conscientiousness }\end{array}$ & $\begin{array}{c}\text { Journal of Applied Social } \\
\text { Psychology } \\
\text { Volume: } 39 \\
\text { Edição: } 6 \\
\text { Páginas: } 1356-1372 \\
\text { Publicado: JUN } 2009 .\end{array}$ & Estados Unidos \\
\hline
\end{tabular}

Fonte. Elaborado pelos autores da pesquisa (2021).

Para a grata surpresa, de todas as pesquisas realizadas, esta foi a que teve os maiores números de resultados, bem como o maior índice de aproveitamento. Foram encontrados 109 trabalhos de autoria ou coautoria de Icek Ajzen, destes foram selecionados 14 para auxiliar nesse estudo (Quadro 5).

Algumas diferenças foram identificadas nessa plataforma, comparando a apresentada anteriormente, e que valem a pena serem ressaltadas. A primeira diferença é que, nesta plataforma, os trabalhos são com datas ressentes, inclusive desse ano, já na outra eram publicações antigas. Outro fato é que, não foi identificado nenhum trabalho em parceria com Martin Fishbein, colega fundador da Teoria da Ação Racional, hipótese para tal fenômeno, pode ser o fato que Fishbein faleceu no ano de 2009 $\mathrm{e}$, os artigos aqui encontrados, possuem datas iguais ou superiores a este ano.

Além da quantia de publicações e seleções de estudos, dos 14 artigos escolhidos, o autor utilizou-se de 11 revistas diferentes para dar publicidade aos resultados de suas pesquisas. Apenas na revista Journal of Applied Social Psychology teve três publicações e, na revista Europes Journal of Psychology teve duas publicações. Já nas demais revistas uma publicação em cada (Quadro 5). Percebe-se assim, que o autor costuma diversificar nos periódicos de publicação de suas pesquisas. Além disso, são revistas conhecidas, importantes e de credibilidade na área de concentração.

Como já mencionado, os artigos do autor publicados nessa plataforma, são contemporâneos, pois as datas de publicações são atuais, inclusive com dois artigos publicados neste ano, o que demonstra que Ajzen encontra-se atuante no meio científico. Além disso, os demais estudos são considerados recentes, pois 03 foram publicados em 2020, 02 em 2019, 02 em 2016 e os mais antigos, que são a minoria, são 01 em 2013, 01 em 2012, 02 em 2011 e 01 em 2009 (Quadro 5).

Ainda, algo que se difere da pesquisa da plataforma anterior, no qual todos os estudos estavam centralizados nos Estados Unidos, nesta temos estudos de outros países também. Mesmo assim, a maioria dos estudos selecionados, são americanos, no caso 09. 03 foram realizados na Alemanha e 02 na Inglaterra (Quadro 5). Podemos considerar a hipótese para esse fenômeno de que os parceiros de estudo de Ajzen, podem ser das localidades mencionadas. Ainda, pode-se ressaltar que todos os estudos foram realizados em países com altos investimentos em ciência.

A Figura 1 apresenta a relação dos títulos dos estudos (pesquisa por palavras) analisados com as variáveis apresentadas. 
Figura 1. Relação títulos e principais variáveis estudadas.

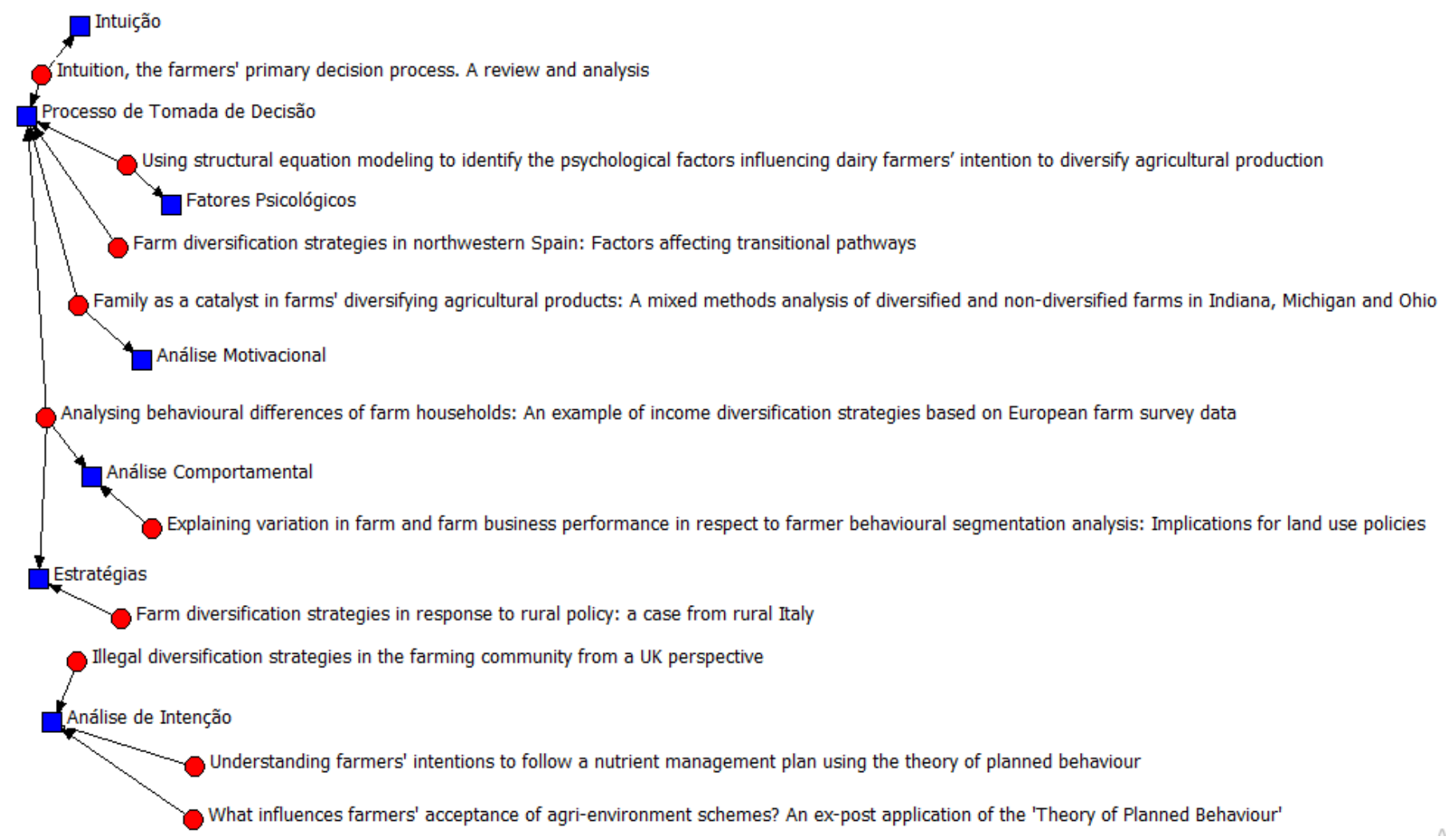

Fonte. Elaborado pelos autores da pesquisa (2021).

Das variáveis estudadas, destaca-se principalmente o processo de tomada de decisão, mencionado na maioria dos estudos. Considerando que a Teoria do Comportamento Planejado e a diversificação ou a especialização são temas bastante debatidos no processo decisório. A utilização da Teoria do Comportamento Planejado serve como aliada no processo de tomada de decisão, pois através dela, é possível medir o nível de intenção de um indivíduo. Já a diversificação ou especialização, é elemento central no processo de tomada de decisão para um agricultor familiar e é através dessa escolha que definirá seu modo produtivo.

Senger et al. (2017), afirmam que medir a intenção entre diversificar ou especializar a produção na agricultura familiar através da Teoria da Ação Racional e da Teoria do Comportamento Planejado, torna-se uma estratégia dentro do processo de tomada de decisão, pois assim, o agricultor terá uma maior certeza sobre suas decisões. Lembrando que, os indivíduos possuem limitações cognitivas, e através dessas teorias há uma maior exatidão no processo de decisão.

Os resultados apresentados por Senger et al. (2017), apontam que a Teoria da Ação Racional teve melhor poder explicativo da intenção dos agricultores em diversificar a produção agrícola do que a Teoria do Comportamento Planejado. Confirmando a base da teoria, os resultados revelaram que atitude e norma subjetiva influenciam positivamente a intenção dos agricultores de diversificar a produção agrícola. Portando, para eles a Teoria da Ação Racional é eficaz no processo de tomada de decisão dos agricultores.

Os autores também afirmam que o processo de tomada de decisão contempla além de aspectos econômicos, os fatores psicológicos, que são aqueles que os indivíduos possuem para processar, assimilar e compreender todos os dados necessários, para optar pela melhor alternativa.

Já Arias et al. (2015), buscaram identificar quais estratégias de diversificação que os agricultores têm empreendido e que são aliadas no processo de tomada de decisão no noroeste da Espanha como diferencial, pois as pesquisas apontam que 
aquela é uma área caracterizada pelo ajuste estrutural tardio. Os autores concluíram que o processo de tomada de decisão pela diversificação ou especialização está ligado tanto em fatores internos quanto externos. Os agricultores que utilizam como estratégia a diversificação têm a concepção que esse modo produtivo reduz riscos. Ainda, são produtores mais jovens que possuem a intenção de diversificar, bem como propriedades menores e com menos recursos. Estes também têm uma preocupação maior com o futuro. Já agricultores mais velhos, com áreas maiores e mais recursos tem maiores tendências a especializar e focar no presente.

Valliant et al. (2017), examinaram as razões do processo de tomada de decisão que levaram os agricultores a decidir pela diversificação da produção. Como resultado, obtiveram dois elementos centrais que estão positivamente associados à perspectiva de diversificação: priorizar a propriedade como algo que os descendentes adultos podem fazer como profissão e ter filhos menores de 18 anos, que além de depender dos pais, que tiram seu sustento dessas propriedades, também podem auxiliar nas rotinas de trabalho da família. Sendo assim, os agricultores familiares optam por diversificar pensando na sobrevivência, futuro e sucessão familiar. No entanto, agricultores com produção não diversificada consideram que ter filhos em casa esteja positivamente associado ao interesse em diversificar, querer que a propriedade empregue descendentes não está.

Portando, para Valliant et al. (2017), é necessária uma análise motivacional para investigação dos sentimentos gerados dentro de cada indivíduo, a partir da sua forma de pensar e interpretar situação de forma favorável ou desfavorável sobre determinado comportamento, para entender o processo de tomada de decisão dos agricultores.

$\mathrm{Na}$ pesquisa de Weltin et al. (2017) após análise comportamental de agricultores, apresentam que a decisão de diversificar as atividades econômicas dentro ou fora da propriedade, depende do negócio agrícola e das características da família. Da mesma maneira que no estudo de Arias et al. (2015), apresentam os agricultores jovens como os mais propensos a diversificar a produção. Os jovens agricultores, com produção orgânica, são mais predispostos a diversificar as atividades, enquanto os tipos de propriedades caracterizados por uma pecuária intensiva e famílias agrícolas já diversificadas e em tempo parcial, são os menos propensos a aplicar esta estratégia. Ainda, uma parcela crescente de agricultores aplica ou aplicaria a diversificação de renda, principalmente fora da propriedade, como estratégia de sobrevivência.

Nathall e Old (2018) buscam relacionar a intuição com o processo de tomada de decisão. Os resultados desse estudo apontaram como melhorar a intuição e sustentar a compreensão dos agricultores e seu modus operandi. Para os autores, a capacidade intuitiva, relativa à capacidade gerencial básica (habilidades de planejamento e implementação), mostrou-se criticamente importante para o alcance dos objetivos.

O principal objetivo da Teoria do Comportamento Planejado é à análise de intenção dos indivíduos em determinado comportamento. Dessa maneira, essa variável foi apresentada em 05 artigos.

De acordo com Schroeder et al. (2015), entender o comportamento dos agricultores faz com que compreendamos suas decisões. Para eles, a utilização da Teoria do Comportamento Planejado é umas das metodologias mais eficazes para à análise de intenção dos agricultores para explicar determinado comportamento. Os resultados dessa pesquisa apontam que as famílias dos agricultores foram classificadas como as de maior e mais positivas pressão social nas decisões dos agricultores. Por outro lado, a opinião de outros agricultores ou da assessoria agrícola, não influenciou muito os agricultores. Outro resultado importante é que quanto maior for à burocracia e documentação exigida para determinada ação, menor a intenção dos agricultores de executar.

Smith et al. (2017) após análise de intenção de agricultores, afirmam que aqueles que optaram pela diversificação da produção têm como principal motivação a sobrevivência econômica da família e da propriedade, além da diminuição de riscos e incertezas.

Já Daxini et al. (2019), realizam pesquisa de análise de intenção utilizando a Teoria do Comportamento Planejado. Os resultados deste estudam demostram que a intenção dos agricultores é principalmente impulsionada pelo controle 
comportamental percebido, seguido pela norma subjetiva e, finalmente, pela atitude. A norma subjetiva é um importante preditor tanto da atitude quanto do controle comportamental percebido. A confiança em fontes técnicas de informação é considerada um determinante mais influente da atitude dos agricultores do que, confiança em fontes de informação social. Esses resultados fornecem uma compreensão abrangente das variáveis que orientam as intenções dos agricultores, ainda destacam a importância das variáveis sociopsicológicas e institucionais na análise da tomada de decisão do agricultor.

Wilson et al. (2013) e Weltin et al. (2017), afirmam que para abordar o processo de tomada de decisão dos agricultores familiares em diversificar ou especializar sua produção é necessário realizar uma análise comportamental desses agricultores, para identificar os motivos e as intenções deles para tal opção produtiva.

Como a base das pesquisas foi sobre a Teoria do Comportamento Planejado, sobre o processo de tomada de decisão dos agricultores familiares em diversificar ou especializar suas produções, identificou-se alguns autores, como: Weltin et al. (2017) e Rosa et al. (2019), que apresentam como uma estratégia a produção agrícola diversificada.

De acordo com Weltin et al. (2017), a diversificação agrícola é uma forma de estratégia para o agricultor familiar, tendo em vista que quando uma cultura estiver em baixa à outra poderá estar em alta financeira, ou ainda, quando ocorrer uma adversidade climática as perdas poderão ter expressão financeira menor daqueles produtores que especializam sua produção.

Rosa et al. (2019) afirmam que, para a agricultura familiar rural a diversificação agrícola além de valorizar a família serve de estratégia para aumentar a produtividade e consequentemente a renda familiar. Da mesma forma, os pesquisadores asseguram que esse modelo produtivo serve como estratégia e aliada do meio ambiente, uma vez que nesse sistema a rotação de culturas é frequente, fazendo que o solo não sofra tanta degradação como na especialização.

Ainda, abordando comportamento humano e o processo de tomada de decisão na agricultura familiar, a intuição é outro fator de relevância que deve ser considerado, porque é através dela que o agricultor percebe, dissemina ou pressente algo, independentemente de raciocínio ou de análise.

Nathall e Old (2018), afirmam que muitas vezes os agricultores passam, mesmo que involuntariamente e inconscientemente, mas pela sua intuição por um processo de tomada de decisão para chegar a uma conclusão sobre algo. Para eles, a intuição é um componente crítico da tomada de decisão dos agricultores e é à base do capital humano. Ainda, os autores apresentam que os pré-requisitos para um bom processo de tomada de decisão pautada na intuição são: experiência, conhecimento técnico e de teoria da decisão e, em parte, habilidades de antecipação. Para os autores, o desenvolvimento de uma intuição bem-sucedida exige ampla consultoria, reflexão pessoal e crítica em uma habilidade de decisão em constante evolução.

Por outro lado, há às variáveis identificadas nas pesquisas realizadas por trabalhos do autor da Teoria do Comportamento Planejado, Icek Ajzen, que possui vários estudos contemporâneos. 
Figura 2. Relação títulos e principais variáveis estudadas.

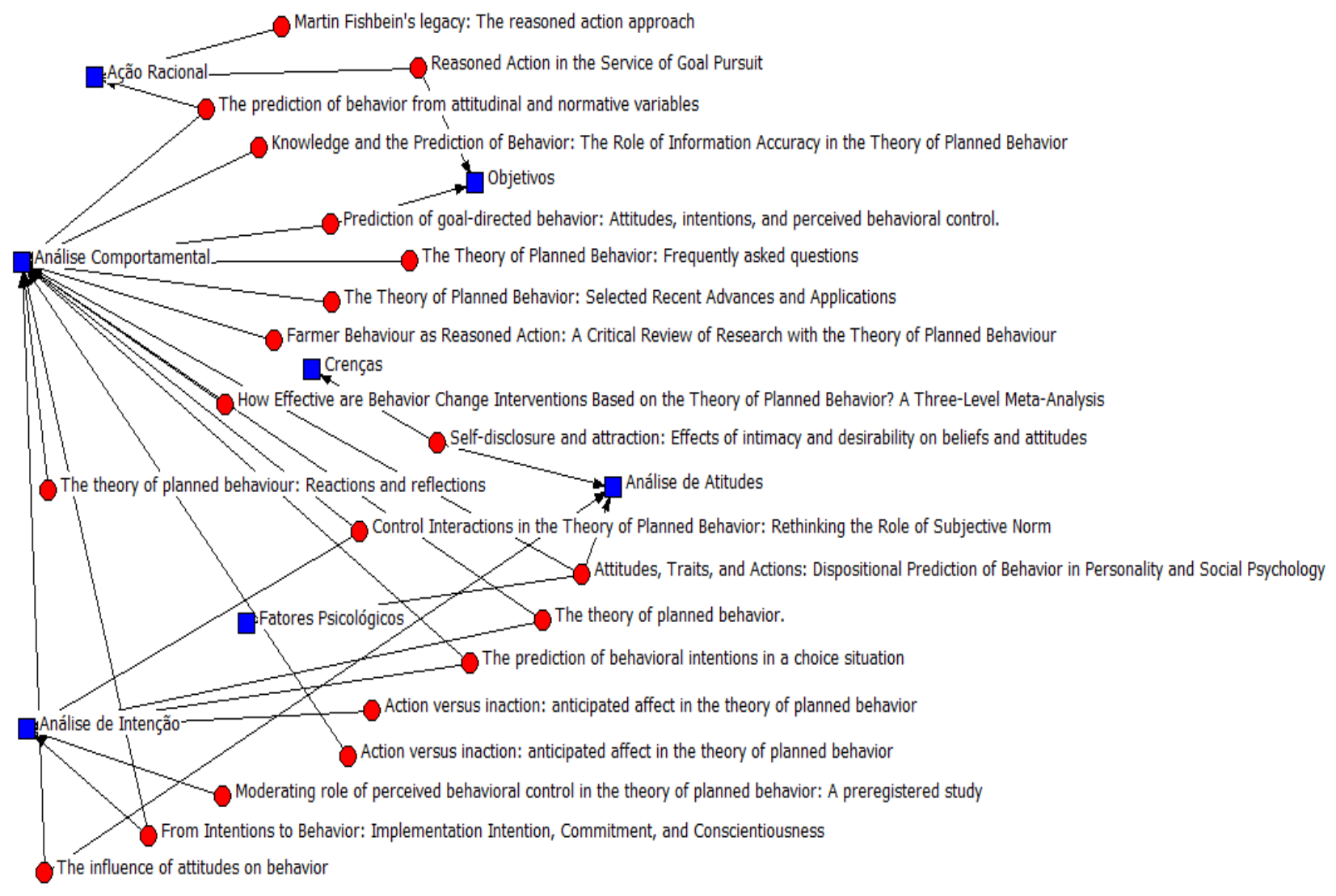

Fonte. Elaborado pelos autores da pesquisa (2021).

Icek Ajzen é um psicólogo social especializado no estudo de análise comportamental humano. Dentre suas várias publicações encontra-se a Teoria do Comportamento Planejado, que tem como objetivo explicar que a intenção do indivíduo em realizar um determinado comportamento. Das obras selecionadas por autoria, 15 apresentam estudos com resultados semelhantes e que enaltecem a análise comportamental (Figura 02). Observa-se que algumas pesquisas são de autoria única de Ajzen e outros em parcerias com outros pesquisadores e variando de trabalhos mais antigos até a atualidade.

Ajzen e Fishbein (1969) apresentam pesquisa sobre análise de intenção e análise comportamental em uma situação de escolha. Os estudiosos concluíram que, as intenções comportamentais em uma situação de escolha, podem ser previstas com maior precisão considerando as atitudes em relação a todas as alternativas comportamentais do que usando a atitude em relação a apenas uma das ações possíveis.

Semelhantemente à pesquisa apresentada anteriormente, Ajzen e Fishbein (1970) publicaram estudo sobre a previsão do comportamento de indivíduos a partir de variáveis e normativas, com base na ação racional. Nessa análise comportamental, os autores afirmam que o comportamento de uma pessoa é resultado de sua intenção comportamental, que é determinada por sua atitude em relação a algum ato e por suas crenças sobre as expectativas dos outros indivíduos, ou seja, crenças normativas e sociais.

Como já apresentando, a Teoria do Comportamento Planejado originou-se sobre a Teoria da Ação Racional, ambas com o objetivo de realizar análise comportamental de indivíduos. Há pesquisadores que afirmam que a Teoria da Ação Racional é eficaz para realização de análise comportamental afirmando que não há necessidade da utilização da Teoria do Comportamento Planejado, e o mesmo fato acontece ao contrário. Com isso, Ajzen e Madden (1986) realizaram experimentos para demonstrar o comportamento humano em busca do alcance de objetivos. Para tanto, utilizaram as duas teorias, e 
concluíram que a Teoria do Comportamento Planejado permitiu uma previsão mais precisa das intenções e do alcance de metas do que a Teoria da Ação Racional.

Ao realizar análise comportamental, Ajzen (1963), apresenta estudos sobre a personalidade e traços dos indivíduos no processo de ações e atitudes. Para ele, esses dois fatores interferem diretamente no processo de tomada de decisão, pois essas questões pessoais acabam sendo consideradas no momento de analisar por qual alternativa decidir.

Semelhantemente, Ajzen e Sheikh (2016), apresentam estudo de análise comportamental como elemento para medir a intenção de um indivíduo. Nesse caso, os autores concluíram que utilizar o afeto para medir a intenção tem significância apenas quando as variáveis da Teoria do Comportamento Planejado são avaliadas em relação a um comportamento de ação ou inação, e que o afeto nessa situação pode ser medido em relação há um comportamento alternativo. Esse estudo é considerado pelos autores como uma errata da pesquisa de Ajzem e Sheikh (2013) que focava com mais expressão a análise de intenção que propriamente em uma perspectiva mais completa de análise de comportamento

Para Ajzen (1987) quando se utiliza da Teoria do Comportamento Planejado além da análise comportamental, é realizada análise de atitudes e a identificação dos fatores psicológicos que levam um indivíduo a tomar uma decisão ou apresentar tal comportamento.

Ajzen (1991) executa análise de intenção para então realizar análise comportamental e afirma que, a partir de atitudes em relação ao comportamento, normas subjetivas e controle comportamental percebido, e essas intenções, juntamente com as percepções de controle comportamental, são responsáveis por uma variação considerável no comportamento real. Neste sentido, a Teoria do Comportamento Planejado está prevendo o comportamento muito bem em comparação com o teto imposto pela confiabilidade comportamental.

No estudo de Flood et al. (2009) foi realizado análise comportamental e análise de intenção, no sentido de demonstrar o caminho percorrido e as interferências de um indivíduo desde a intenção até a realização desse comportamento. Como resultado, os autores obtiveram que a intenção de fazer algo varia em sua especificidade e cada situação e que o indivíduo tem uma forma de comportamento para tal.

Em alguns estudos de Ajzen (2011), Steinmetz et al. (2016), Ajzen et al. (2019), Barbela e Ajzen (2020), Ajzen (2020) e Bosnijak et al. (2020), são apresentados resultados teóricos e conceituais semelhantes, no qual são tratados vários aspectos da Teoria do Comportamento Planejado, realizando revisão da teoria, atualização, abordando alguns problemas e questionamentos não respondidos e as discutindo. Além disso, demonstra a influência e às reações e reflexões sobre essa teoria. Entre os tópicos abordados estão à natureza das intenções e os limites da validade preditiva, racionalidade, afeto, emoções, comportamento e hábitos passados, os modelos, traços de personalidade e tendência de comparação social, elementos essenciais para análise comportamental.

Ajzen et al, (2011) ao relacionar análise comportamental e informação, apresentam resultados que questionam a suposição comum de que, estar bem-informado é um pré-requisito para uma ação eficaz produzir os resultados desejados. Para eles, o conhecimento é uma condição necessária, mas não suficiente. Na perspectiva da Teoria do Comportamento Planejado, muitas vezes a informação pode ser irrelevante para a tomada de decisão. Em vez disso, o que determina intenções e ações, são informações subjetivamente mantidas (ou seja, crenças) que vincula um comportamento de interesse a um comportamento positivo, ou resultados negativos às expectativas normativas de indivíduos ou grupos de referência importantes e, para controlar fatores que podem facilitar ou inibir o desempenho do comportamento. Se essas informações são precisas ou imprecisas, é irrelevante.

O trabalho de Sok et al. (2020) traz informações e resultados muito relevantes, tendo em vista que os autores realizaram pesquisa sistemática sobre análise comportamental de agricultores através da Teoria do Comportamento Planejado e, concluíram que muitas pesquisas publicadas não estão aplicando corretamente essa teoria com temática. Após análise de 124 
trabalhos, os pesquisadores apontaram as principais falhas dos estudos analisados. Alguns, ou mesmo a maioria dos construtos da teoria não foram avaliados, tornando impossível um teste adequado. O princípio da compatibilidade não é observado, prejudicando a validade preditiva da teoria. Novos preditores são propostos sem testar a quantidade de variância adicional na intenção e ou comportamento que pode ser explicada por essas variáveis. Os fatores de fundo são tratados como preditores diretos de intenção ou comportamento, quando se espera que seus efeitos sejam mediados pelos preditores proximais da teoria ou moderem as relações entre os construtos da teoria.

A utilização da Teoria do Comportamento Planejado tem como objetivo análise de intenção dos indivíduos. Através dessa análise é possível aferir o nível de intenção para desenvolver algum comportamento. Com essa medição o processo de tomada de decisão torna-se mais eficaz, uma vez que se sabe o nível de intenção de que o indivíduo possui. Portando, é outra variável expressiva nos artigos selecionados, inclusive, alguns já apresentados anteriormente.

Neste sentido Barbera e Ajzen (2021) apresentam estudo que leva em consideração a análise de intenção para explicar o comportamento dos indivíduos através da Teoria do Comportamento Planejado. Os resultados apontam que à medida que os escores de controle comportamental percebido aumentam a força da associação entre atitude e intenção também aumenta, enquanto a força da associação entre norma subjetiva e intenção diminui.

Da mesma maneira, Ajzen et al. 2019), apontam para a necessidade da realização de análise de intenção para compreender o comportamento humano. Para os autores, medir a intenção dos indivíduos através da Teoria do Comportamento Planejado é forte aliada para explicar e justificar o comportamento.

A abordagem da ação racional da qual Martin Fishbein foi pioneiro, explica o comportamento humano em termos de consideração que são direcionados quando as pessoas pensam em realizar um comportamento em questão. Para Ajzen (2012), a utilização da Teoria do Comportamento Planejado é a melhor ferramenta para entender o comportamento dos indivíduos, pois através dela é possível identificar que as crenças comportamentais, normativas e de controle, fornecem a base, respectivamente, para as atitudes em relação ao comportamento, normas subjetivas e controle comportamental percebido. Esses três fatores, são responsáveis por uma grande variação nas intenções comportamentais e que, as intenções e o controle percebido podem ser usados para prever o comportamento real.

Ajzen e Kruglanski (2019) analisaram o ser humano em busca por objetivos através da ação racional e concluíram que, a formação de uma intenção comportamental é determinada pela motivação para realizar um comportamento através das opções, alternativas e no contexto dos objetivos ativos no momento do indivíduo.

Na pesquisa de Dalmo et al. (1979), é possível averiguar que, para compreender o comportamento humano é necessário a análise de atitude e a investigação das crenças desses indivíduos, por muitas vezem explicadas através das convicções e da fé, os motivos que levam um indivíduo para algum comportamento.

\section{Conclusão}

Após a realização de revisão nas plataformas Scopus e Web of Science identificou-se um rico catálogo de estudos utilizando o termo Teoria do Comportamento Planejado, e destes vários com forte ligação na agricultura familiar, no processo de tomada de decisão, na diversificação e especialização de culturas, e outros, principalmente na pesquisa pela autoria, com rica base conceitual sobre a teoria.

Nas consultas realizadas por palavras-chaves, percebeu-se que houve um aumento de pesquisas sobre a temática no ano de 2018, mas voltando a uma estagnação após esse período. Outro fato que chama atenção, é que há trabalhos em diversos países sobre $\mathrm{o}$ assunto. 
As variáveis que se destacaram na revisão por palavras-chaves foram: processo de tomada de decisão, análise de intenção, fatores psicológicos, análise comportamental, análise motivacional, estratégia e intuição estão interligados, geralmente no que diz respeito ao comportamento humano e suas escolhas.

Já na pesquisa realizada pelo autor da Teoria do Comportamento Planejado, Icek Ajzen, percebeu-se que psicólogo está ativamente ligado a pesquisa e a publicação. Suas pesquisas são realizadas em diversos países e sobre as localidades de publicação, grande parte ocorreu nos Estados Unidos, país em que Ajzen reside.

Um fenômeno que merece ser destacado, é que na plataforma Scopus o número de trabalhos publicados de autoria ou participação são menores, ainda, trabalhos mais antigos e com menos autores participantes. Já na plataforma Web of Science o número de trabalhos de Ajzen são muito mais expressivos, contemporâneos e com mais participantes em suas pesquisas.

A análise comportamental é a variável predominante nos trabalhos do autor, haja vista que Ajzen é psicólogo e pesquisador do comportamento humano. Destaca-se também a variável análise de intenção, que é o objetivo da Teoria do Comportamento Planejado, ainda, análise de atitude, que é um dos constructos de estudo da teoria. Ação racional também ganha notoriedade nos estudos, que vale ressaltar que foi a base da teoria que antecedia a Teoria do Comportamento Planejado, que ainda aparece com expressão em vários trabalhos do autor. Com menos expressividade, aparecem as variáveis: estratégia e crenças. Há primeira muito utilizada em trabalhos sobre tomada de decisão e a segunda, ligada a pesquisas relacionadas sobre o que levam um indivíduo para algum comportamento.

Foi possível observar que há várias pesquisas que relacionam a Teoria do Comportamento Planejado no processo de tomada de decisão dos agricultores familiares pela diversificação ou especialização da produção. Nestes estudos, os autores apontam que a utilização dessa teoria serve como estratégia para compreendermos as intenções desses agricultores em sua decisão.

Por outro lado, o fundador da Teoria do Comportamento Planejado, Icek Ajzen, em algumas publicações critica que há muitas pesquisas que não utilizam adequadamente a teoria em seus estudos. De acordo com ele, o pesquisador precisa conhecer toda aplicabilidade dessa teoria, para assim, ter uma maior exatidão nos resultados sobre a intenção dos indivíduos para um determinado comportamento.

Os estudos apontam que a intenção dos agricultores pela diversificação da produção é mais expressiva que a especialização. Muitos agricultores que utilizam a diversificação da produção trabalham com esse modelo como estratégia de segurança financeira. Por exemplo, quando uma cultura não estiver rentável, a outra cultura dá o suporte necessário para manter o equilíbrio financeiro. Além disso, são agricultores preocupados com o sustento da família.

As pesquisas concluíram que propriedades rurais que possuem a metodologia da diversificação se desenvolvem mais do que aquelas que produzem apenas uma cultura. Para eles, a diversificação também serve como grande aliada do meio ambiente, uma vez que nesse sistema a rotação de culturas é frequente, fazendo que o solo não sofra tanta degradação como na monocultura. O perfil desses agricultores é de proprietários de pequenas áreas de terras, jovens e com menos recursos. Estes também têm uma preocupação maior com o futuro. Já agricultores mais velhos, com áreas maiores e mais recursos tem maiores tendências a especializar e focar no presente.

Desta maneira, a utilização da Teoria do Comportamento Planejado auxilia o pesquisador a identificar a intenção dos agricultores familiares no processo de tomada de decisão pela diversificação ou especialização da produção, além de ajudar esse agricultor a ter uma maior certeza em suas decisões, pois através dessa teoria ele será capaz de medir as consequências, vantagens e desvantagens, a opinião da família, amigos, vizinhos e equipe de atendimento técnico da propriedade, bem como medir sua capacidade em diversificar ou especializar a sua produção.

A realização de uma revisão sistêmica é de extrema importância, haja vista que é possível identificar o que está sendo pesquisado e discutido no mundo sobre determinada temática. Portando, após a realização dessa revisão, percebe-se que a 
Research, Society and Development, v. 11, n. 1, e15211124934, 2022

(CC BY 4.0) | ISSN 2525-3409 | DOI: http://dx.doi.org/10.33448/rsd-v11i1.24934

Teoria do Comportamento Planejado está sendo muito utilizada por pesquisadores das mais diversas áreas, bem como, no foco desse artigo, que é o processo de tomada de decisão dos agricultores familiares na escolha de diversificar ou especializar a produção, mas como lacuna de pesquisa, identificou-se que não há estudos que relacionam todos esses temas.

\section{Referências}

Abramovay, R. (1992). Paradigmas do capitalismo agrário em questão. Hucitec/Anpocs/Unicamp.

Abramovay, R. (1992). Uma nova extensão para a agricultura familiar. Anais [...] Seminário Nacional de Assistência Técnica e Extensão Rural. 1997.

Ajzen, I. (1987). Attitudes, traits, and actions: dispositional prediction of behavior in personality and social psychology. Advances in Experimental Social Psychology. 20, 1-63.

Ajzen, I. (1991). The theory of planned behavior. Organizational behavior and human decision processes. Amsterdan. 50(2), 179 - 211.

Ajzen, I. (2005). Attitudes, personality and behavior. 2 ed. Maidenhead: Open University Press.

Ajzen, I. (2011). The Theory of Planned Behaviour: reactions and reflections. Psychology and Health. 26(9), 1113-27

Ajzen, I. (2012). Martin Fishbein's legacy: the reasoned action approach. Annals [...] The American Academy of Political and Social Science. 643, 11-27

Ajzen, I. (2020). The theory of planned behavior: Frequently asked questions. Wiley Periodicals, Hum Behav \& Emerg Tech. 2: 314-24.

Ajzen, I., Czasch, C. \& Flood, M. G (2009). From intentions to behavior: implementation intention, commitment and conscientiousness. Applied Social Psychology. 39(6), 1356-1372.

Ajzen, I. \& Fishbein, M. (1969). The prediction of behavioral intentions in a choice situation. Experimental Social Psychology. 05(4), $400-416$.

Ajzen, I. \& Fishbein, M. (1970). The prediction of behavioral from attitudinal and normative variables. Experimental Social Psychology. 06(4), $466-487$.

Ajzen, I. \& Fishbein, M. (1980). Understanding attitudes and predicting social behaviour. Englewood Cliffs: Prentice-Hall.

Ajzen, I., Fishbein, M.; Lohmann, S. \& Albarracín, D. (2019). The influence of attitudes on behaviour. Nova York: Routledge..

Ajzen, I.; Joyce, N., Sheikh, S. \& Cote, N. G. (2011). Knowledge and the Prediction of Behavior: the role of information accuracy in the Theory of Planned Behavior. Basic and Applied Social Psychology. 33(2), 101-117.

Ajzen, I. \& Kruglanski, A. (2019). Reasoned action in the service of goal pursuit. Psychological Review. 126(5), 774-786.

Ajzen, I. \& Madden, T. J. (1986). Prediction of goal-directed behavior: attitudes, intentions, and perceived behavioral control. Experimental Social Psychology. 22(5), 453-474.

Ajzen, I. \& Sheikh, S. (2013). Action versus inaction: anticipated affect in the Theory of Planned Behavior. Journal of Applied Social Psychology. 43(1), 155162.

Ajzen, I. \& Sheikh, S. (2016). Action versus inaction: anticipated affect in the Theory of Planned Behavior. Journal of Applied Social Psychology. 46(5), 313314.

Amarante, E. A. L., Fülber, V. M., Zonin, W., Novakoski, R. \& Plein, C. (2018). Agricultura familiar e a sustentabilidade: novos arranjos e processos. Braz. J. of Develop. 4(7), 4419-4432.

Arias, A. I. G., Gonzáles, I. V., Garcia, F. S. \& Fra. M. P. (2015). Farm diversification strategies in northwestern Spain: factors affecting transitional pathways. Land Use Policy. 49(1), 413-425.

Balestrin, A. (2002). Uma análise da contribuição de Herbert Simon para as teorias organizacionais. Read. 8(4), 1-17.

Barbera, F. L.\& Ajzen, I. (2020). Control interactions in the Theory of Planned Behavior: rethinking the role of subjective norm. Europe's Journal of Psychology. 16(3), 401-417.

Barbera, F. L.\& Ajzen, I. (2021). Moderating role of perceived behavioral control in the Theory of Planned Behavior: a preregistered study. Theoretical Social Psychology. 05(1), 35-45.

Barbieri, C. \& Mahoney, E. (2009). Why is diversification an attractive farm adjustment strategy? Insights from Texas farmers and ranchers. Journal of Rural Studies. 25(1), 58- 66

Barros, G.(2004). Racionalidade e organizações: um estudo sobre comportamento econômico na obra de Herbet A. Simon (Dissertação de mestrado, Universidade de São Paulo, São Paulo, Brasil).

Borges, J. A. R. (2015). General Discussion. In: Borges, J. A. R. The role of psychological factors in the adoption of improved natural grassland by Brazilian cattle farmers in biome pampa. Thesis (PhD Business Economics) Wageningen University, Wageningen, NL. 
Research, Society and Development, v. 11, n. 1, e15211124934, 2022

(CC BY 4.0) | ISSN 2525-3409 | DOI: http://dx.doi.org/10.33448/rsd-v11i1.24934

Bosnijak, M., Ajzen, I. \& Schmidt, P. (2020). The Theory of Planned Behavior: selected recent advances and applications. Europe's Journal of Psychology. $16(3), 352-356$

Burton, R. J. F. (2004). Reconceptualising the 'behavioural approach' in agricultural studies: a socio-psychological perspective. Rural Studies 20 (1), 359-371.

Choo, C. W. (2003). A organização do conhecimento: como as organizações usam a informação para criar significado, construir conhecimento e tomar decisões. São Paulo: SENAC.

Colognese, S. A. \& Stoffel, J. A. (2007). Organização produtiva da agricultura familiar no Oeste do Paraná. In: Migrações e a construção do Oeste do Paraná. Cascavel: Coluna do Saber.

Dalcin, D. (2010). O processo de tomada de decisão em agricultores de Boa Vista das Missões - RS (Dissertação de mestrado, Universidade Federal de Santa Maria, Rio Grande do Sul, Brasil).

Dalto, C. A., Ajzen, I. \& Kaplan, K. J. Self-disclosure and attraction: effects of intimacy and desirability on beliefs and attitudes. Research in Personality. 13(2), 127-138.

Daxini, A., Ryan. M., O’Donoghue, C. \& Barnes, A. P. (2019). Understanding farmers' intentions to follow a nutrient management plan using the theory of planned behaviour. Land Use Policy. 85(1), 428-437.

Ellis, F. (2000). Rural livelihoods and diversity in developing countries. Oxford University.

Feitosa, Z. O. (2017). Modelo conceitual das motivações conscientes e não conscientes do comportamento de uso do automóvel com base na Teoria do Comportamento Planejado-TCP (Tese de doutorado, Universidade Nacional de Brasília, Distrito Federal, Brasil).

Garner, C. A. (1987). Uncertainty, human judgment and economic decisions. Post Keynesian Economics. 05(3), 413-424.

Gil, A. C. (2002). Como elaborar projetos de pesquisa. (4a ed.), Atlas.

Gomes, L. F. A. M. \& Gomes, C. F. S. (2019). Princípios e métodos para tomada de decisão. (6a ed.), Atlas.

Götsch, E. (2000). Homem e natureza: cultura na agricultura. Centro Sabiá.

Graziano Da Silva, J. (Coord.). (1978). Estrutura agrária e produção de subsistência na agricultura brasileira. Hucitec.

Guimaraes, A. P. (1963). Quatro séculos de latifúndio. Paz e Terra.

Hansson, H. \& Ferguson, R. (2011). Factors influencing the strategic decision to further develop dairy production: A study of farmers in central Sweden. Livestock Science. 135(2-3), 110 - 123.

Hanzi, M. (2000). Polycultures in the Brazilian drylands: A new version of an old tradition. Aridlands Newsletter. 48(1), 01-09.

Hoffmann, R., Serrano, O., Neves, E. M., Thame, A. C. de M. \& Engler J. J. de C. (1987). Administração da empresa agrícola. (7a ed.), Pioneira.

IBGE População. (2021). População Brasileira. http://www.ibge.gov.br/populacao//.

Ilbery, B. W. (1991). Farm diversification as an adjustment strategy on the urban fringe of the West Midlands, Rural Studies. 7(3), 207 - 218.

Koller, S. H., Couto, M. C. P. \& Hohendorff, J. V. (2014). Manual de produção cientifica. Editora Pensa.

Lamarche, H. (Coord.). (1999). A agricultura familiar II: do mito à realidade. Campinas: Editora da UNICAMP.

Lei n. 11326. (2006). Estabelece as diretrizes para a formulação da Política Nacional da Agricultura Familiar e Empreendimentos Familiares Rurais. Diário Oficial da Republica.

Marconi, M. A. \& Lakatos, E. M. (2010). Fundamentos de metodologia científica. Editora Atlas.

Maximiano, A. C. A. (200). Introdução à administração. (5a ed.), Atlas.

Nathall, P., \& Old; K. Intuition, the farmers’ primary decision process. A review and analysis. Rural Studies. 58(1), 28-38.

Norder, L. A C. (2009). Mercantilização da agricultura e desenvolvimento territorial. In: Schneider, S. (Org.) A diversidade da Agricultura Familiar. 2 ed. Porto Alegre: UFRGS.

Perondi, M. A. \& Schneider, S. (2021). Diversificação agrícola e não agrícola da agricultura familiar. http://www.ufrgs.br/pgdr/publicacoes/producaotextual/. Plein, C. (2016). Desenvolvimento, mercados e agricultura familiar: uma abordagem institucional da pobreza rural. CRV.

Ploeg, J. D. Van Der. (2016). Camponeses e a arte da agricultura: um manifesto chayanoviano. UFRGS/UNESP.

Ploeg, J. D. Van Der. \& Roep, D. (2003). Multifunctionality and rural development the actual situation in Europe. In: Huylenbroeck, G. Van. \& Durand, G. (Eds.), Multifunctional Agriculture. A New Paradigm for European Agriculture and Rural Development. Ashgate, Aldershot, Hampshire, England.

Robbins, S. P., Judge, T. A. \& Sobral, F. (2010). Comportamento Organizacional: teoria e prática no contexto brasileiro. (14a ed.), Pearson Prentice Hall.

Romeiro, A. R. (1998). Meio Ambiente e Dinâmica de Inovações na Agricultura. AnnaBlume. 
Rosa, N. P. D. (2018). Fatores sociopsicológicos que influenciam os produtores da região meio oeste catarinense a adotarem melhorias no sistema de produção de leite à base de pastagem perene (Tese de doutorado, Universidade Federal do Rio Grande do Sul. Rio Grande do Sul, Brasil).

Rosa, M. D., Mcelwee. G. \& Smith. R. (2019). Farm diversification strategies in response to rural policy: a case from rural Italy. Land use policy. 81(1), 291301.

Sampaio, R. F. \& Mancini, M. C. (2007). Estudo de revisão sistemática: um guia para síntese criteriosa da evidência cientifica. Revista Brasileira de Fisioterapia. 11(1), 83-89.

Schäffer, C. J. De O. (2011). A diversificação de atividades agrícolas na agricultura familiar do munícipio de sertão Santana, RS, a partir do programa municipal de incentivo à viticultura (Monografia De Mestrado, Universidade Federal Do Rio Grande do Sul. Rio Grande Do Sul, Brasil).

Schroeder, L. A. \& Chaplin, S; Isselstein, J. (2015). What influences farmers' acceptance of agri-environment schemes? An ex-post application of the “Theory of Planned Behaviour". Landbau Forschung. 65(1), 15-28.

Senger, I. (2016). Compreensão dos fatores psicológicos que afetam a tomada de decisão dos agricultores familiares na diversificação da produção: uma aplicação da Teoria Do Comportamento Planejado (Tese de doutorado, Universidade Federal do Rio Grande do Sul, Rio Grande do Sul, Brasil).

Senger, I., Borges, J. A. R. \& Machado, J. A. D. Using structural equation modeling to identify the psychological factors influencing dairy farmers' intention to diversify agricultural production. Livestock Science, 203, 97-105, 2017.

Schneider, S. (1999). Agricultura Familiar e Industrialização: pluriatividade e descentralização industrial no Rio Grande do Sul. UFRGS.

Schneider, S. (2003). A pluriatividade na agricultura familiar. UFRGS.

Schneider, S. (2003). Teoria social, agricultura familiar e pluriatividade. Revista Brasileira de Ciências Sociais. 18(51), 99-122.

Schneider, S. (2010). Referências para a elaboração de uma matriz (template) de análise da diversificação da produção em áreas cultivadas com tabaco no Brasil. Porto Alegre: UFRGS.

Schneider, S. (2010). Diversificação como estratégia de desenvolvimento rural: referências teóricas para construção de alternativas economicamente sustentáveis de diversificação da produção e renda em áreas de cultivo de tabaco no Brasil. UFRGS.

Simon, H. A. (1957). Models of man: social and rational: mathematical essays on rational human behavior in a social setting. Nova Iorque: John Wiley e Sons.

Simon, H. A. (1963). A capacidade de decisão e de liderança. Harper and Brothers Publischers.

Simon, H. A. (1979). Comportamento administrativo: estudo dos processos decisórios nas organizações administrativas. (3a ed.), Fundação Getúlio Vargas.

Smith, R., Mcelwee, G. \& Somorviller, P. (2017). Illegal diversification strategies in the farming community from a UK perspective. Rural Studies. 53(1), $122-131$.

Sok, J., Borges, J. R., Schmidt, P. \& Ajzen, I. (2020). Farmer behaviour as reasoned action: A critical review of research with the theory of planned behaviour. Agricultural Economics.

Spiegel, T. \& Caulliraux, H. M. (2017). A tomada de decisão diante da racionalidade limitada: revisão da literatura. CIÊNCIA E COGNIÇÃO. 18(2).

Steinmetz, H., Knappstein, M., Ajzen, I., Scmidt, P. \& Kabst, R. (2016). How efetive are behavior change interventions based on the Theory of Planned Behavior? A Thee-Level Meta-Analysis. Psychology. 224(3), 215-233.

Turner, M., Whitehead, D., Barr, D., Fogerty, M., Errington, A., Lobley, M. \& Reed, M.(2003). Farm Diversification Activities: Benchmarking Study 2002. https://socialsciences.exeter.ac.uk//.

Veiga, J. E. da. (1991). O desenvolvimento agrícola. USP/HUCITEC. 1991.

Veiga, J. E. da. (2007). O desenvolvimento agrícola: uma visão histórica. (2a ed.), Edusp.

Valliant, J. C. D., Farmer, J. R., Dickinson, S. L., Bruce, A. B. \& Robinson, J. M. (2017). Family as a catalyst in farms' diversifying agricultural products: A mixed methods analysis of diversified and non-diversified farms in Indiana, Michigan and Ohio. Rural Studies. 55(1), 303-315.

Weltin, M., Zasada, I., Franke, C., Piorr, A., Raggi, M. \& Viaggi, D. (2017). Analysing behavioural differences of farm households: an example of income diversification strategies based on European farm survey data. Land Use Policy. 6(1), 172-184.

Willock, J., Deary, I. J., Edwards-Jones, G., Gibson, G. J., Mcgregor, M. J., Sutherland, A., Dent, J. B. \& Morgan, O., Grieve, R. (1999) The Role of Attitudes and Objectives in Farmer Decision Making: Business and Environmentally Oriented Behaviour in Scotland. Agrincural Economics. 50(2), 286-303.

Willock, J., Deary, I. J., Mcgregor, M. M., Sutherland, A., Edwardsjones, G., Morgan, O., Dent, B., Grieve, R. \& Gibson, G. Austin, E. (1999). Farmers' Attitudes, Objectives, Behaviors, and Personality Traits: The Edinburgh Study of Decision Making on Farms. Vocational Behavior. 54(1), 5-36.

Wilson, P., Hasper, N. \& Darling, R. (2013). Explaining variation in farm and farm business performance in respect to farmer behavioural segmentation analysis: implications for land use policies. Land Use Policy. 30(1), 147-156. 